Reviews in Digital Humanities • Vol. 2, No. 4

\title{
Editors' Note: April 2021
}

Jennifer Guiliano' ${ }^{1}$, Roopika Risam ${ }^{2}$, Tanya Clement ${ }^{3}$

${ }^{1}$ IUPUI, ${ }^{2}$ Salem State University, ${ }^{3}$ University of Texas at Austin

Published on: Apr 12, 2021

License: Creative Commons Attribution 4.0 International License (CC-BY 4.0). 


\section{Editors' Note}

\section{Jennifer Guiliano and Roopika Risam}

Reviews in Digital Humanities has been an ongoing experiment in building the capacity of digital humanists to offer peer reviews that blend humanistic and technical inquiry. To this point, we've focused on capacity building with faculty, staff, cultural heritage professionals, and individual graduate students. In this issue, we experiment with scaling the work of capacity building by partnering with a class of graduate students and their instructor. Tanya Clement, in the Department of English at University of Texas, was our willing partner as we explored whether we could introduce students to the Reviews model and train them to analyze projects and produce reviews over the course of a semester. As you'll see from Clement's guest editor's note below, the short answer is yes. Clement's students produced thirteen publishable reviews, which will be published across three issues.

To help Clement, we provided access to our submissions spreadsheet that tracks projects that have been nominated for review. With her students, she selected projects from that list and augmented them with other projects that students were interested in reviewing. We then solicited project overviews from project directors so by the time classes started for fall semester, students had access to raw materials. At the outset of their sequence of assignments related to Reviews, we met virtually with the students. We explained the motivation behind our experiment, reviewed our workflow, and answered their questions about what reviewing does in the discipline. Clement, as their instructor, then took over by teaching them how to review. Below, she describes how that work occurred. We're pleased with the results of the experiments and extend our deepest thanks to Clement and her students.

Generally, the process for using Reviews in a course is as follows:

- Three months prior to the start of the course: contact Reviews to propose your student issue. Please provide us with a description of the course, including the estimated number of students. If you wish to do a thematic issue, please share the theme you wish your students to pursue.

- We will then schedule a call with you to identify potential projects from the open submissions we've received as well as generate a list of projects to invite, if necessary. Usually, we'll ask for at least 4-6 projects more than the number of total 
reviews you intend to publish. This allows us to account for projects that are not ready to review or cannot participate.

- 60 days prior to the start of course: We will send invitations to project directors to solicit overviews. Most overviews are returned in 45 days.

- 30 days prior to the start of the course: Schedule class meetings where Reviews editors will participate.

- Semester work: Students work with their instructor based on the timeline agreed upon in the course syllabus. Reviews editors can participate in revising project reviews, as needed. Once reviews are finalized, the instructor writes an editorial note and shares all final reviews and the guest editor note to Reviews for publication.

Our aim is that course-based Reviews issues are published the semester following the course, when possible.

If you are considering integrating Reviews into a course, drop us a note! You can also submit a project for review, nominate a project you admire, volunteer for our reviewer pool, and tell your colleagues and students about the journal.

Questions? Thoughts? Concerns? Contact the editors, Jennifer Guiliano and Roopika Risam, by email or through the Twitter hashtag \#ReviewsInDH.

\section{Guest Editor's Note}

\section{Tanya Clement}

For 10 years, I've been teaching a graduate-level Introduction to Digital Humanities course at the University of Texas, first in the School of Information and more recently in the Department of English. The class has historically attracted students from the School of Information and departments across the College of Liberal Arts, including African and African Diaspora Studies, American Studies, Classics, English, Geography, History, and Spanish and Portuguese. My goal in teaching the course is to empower students to engage in digital humanities research and scholarship based on their own interests and academic contexts. To that end, I want students to leave the course with a better understanding of digital humanities research goals, methodologies, and scholarship venues, including conferences, book series, journals, and projects across disciplines. I want them to know enough to either move ahead with a rigorous digital humanities agenda in their own research or to walk away with a better sense of digital humanities knowledge production as complementary to their own fields of study. This special issue of Reviews in Digital Humanities represents one type of pedagogical 
activity in the classroom: the review essay. This issue represents the work of my students as they developed proficiency in evaluating digital projects.

Reviews has been a fantastic resource for the course. It provides an up-to-date picture of digital humanities projects across a range of topic areas with varied resources, methodologies, and platforms. The overview explains the who, what, why, and how behind each project, while the review puts each project in context with related research. Further - and perhaps most importantly for preparing for my course and as a later resource for my students - projects are made discoverable by the Reviews keywords. Finding digital humanities projects across the web that are good examples for students is impossibly difficult; finding good digital humanities projects in Reviews is a breeze. In addition, the structure of the reviews, which asks reviewers to include an assessment of the project's humanistic claims and evidence, assessment of the technology used/developed, and analysis of the project and its place within existing scholarship and technological practices, aligns with my own criteria for students. I want them to understand that digital humanities is not just about using digital tools in the humanities. Rather, as Reviews shows, thinking critically about the role that digital methodologies play in knowledge production is at the heart of digital humanities research and scholarship. Writing a review for the journal was a natural project for the course as it aligned with what I wanted to teach students about thinking critically about and within digital humanities. Finally, in Reviews, the students have a public platform on which to publish their work in a safe and guided environment facilitated by me but more so by editors Guiliano and Risam.

Managing the students' review-writing process was straightforward. I worked with Guiliano and Risam on identifying ten projects we thought students would be interested in reviewing. Eight project directors wrote back with overviews. In teams of two, my students read previously published reviews from the journal, and we discussed them and the review criteria in class. Students chose projects they wanted to review and, over the course of six weeks, we wrote drafts together, shared drafts with each other, and wrote and shared peer reviews in small groups. I gave them feedback (and took some for my own review) and offered them the opportunity to make changes needed for publication. Each student in the course chose to work toward publication.

The issue you find here represents the collaborative review culture in my classroom. And, importantly, it suggests one avenue for broadening opportunities for students to publish their coursework to assist the field as a whole. Enjoy!

Part 1 (February 2021): 
- Louisiana Slave Conspiracies, reviewed by Keerti Arora and Anna Lawrence;

- On the Books: Jim Crow and Algorithms of Resistance, reviewed by Ann Marie Blackmon and Caroline Collins;

- Slave Revolt in Jamaica, 1760-1761, reviewed by Ethan Warren;

- Relaciones Geográficas, reviewed by Anna Lawrence and Keerti Arora; and

- The Anti-Eviction Mapping Project, reviewed by Tanya Clement.

Part 2 (March 2021):

- Media History Digital Library, reviewed by Nina Gary and Becky Yatsuknenko;

- SongData, reviewed by Carl Teegerstrom and Kayleigh Voss;

- Furious Flower Digital Archive, reviewed by Gabrielle Roth; and

- Tribesourcing Southwest Film Project, reviewed by Carl Teegerstrom.

Part 3 (April 2021):

- The Collective Biographies of Women, reviewed by Ali Gunnells;

- Mapping the Gay Guides, reviewed by Katherin Tairo-Quispe;

- The Lesbian and Gay Liberation in Canada Prosopography Project, reviewed by Becky Yatsuknenko and Nina Gary;

- Readux, reviewed by James Lacitignola; and

- Distant Viewing Toolkit, reviewed by Patrick Sui. 